\title{
Effect of Silicon and Host Resistance on Sheath Blight Development in Rice
}

\author{
F. Á. Rodrigues, Graduate Research Assistant, University of Florida-IFAS, Plant Pathology Department, Gaines- \\ ville, FL, 32611-0680; L. E. Datnoff, Professor of Plant Pathology, University of Florida-IFAS, Everglades Re- \\ search \& Education Center, Belle Glade, FL, 33430-8003; G. H. Korndörfer, Professor of Soil Science, Federal \\ University of Uberlândia, ICIAG, Uberlândia, Minas Gerais, Brazil, 38400-902; K. W. Seebold, Former Graduate \\ Research Assistant, University of Florida-IFAS, Plant Pathology Department, Gainesville 32611-0680; M. C. Rush, \\ Professor of Plant Pathology, Department of Plant Pathology, LSU, Baton Rouge, LA 70803
}

\begin{abstract}
Rodrigues, F. Á., Datnoff, L. E., Korndörfer, G. H., Seebold, K. W., and Rush, M. C. 2001. Effect of silicon and host resistance on sheath blight development in rice. Plant Dis. 85:827-832.

Rice cultivars high in partial resistance (Jasmine, LSBR-5), moderately susceptible (Drew and Kaybonnet), and susceptible (Lemont and Labelle) to sheath blight were grown in a silicondeficient Histosol with and without calcium silicate slag. The treatment with silicon increased the concentration of this element in plant tissue by $80 \%$ over all experiments. Fertilization with silicon significantly reduced the severity of sheath blight, and the total area under the vertical lesion extension progress curve on moderately susceptible and susceptible cultivars compared to those cultivars high in partial resistance without silicon. The percentage of infected tillers was significantly reduced by $82,42,28,41,26$, and $17 \%$ respectively for Jasmine, LSBR-5, Drew, Kaybonnet, Lemont, and Labelle, when silicon was applied, over all experiments. Dry matter accumulation was significantly greater with added silicon. In the absence of disease, silicon enhanced dry matter accumulation by $15 \%$ over the control, whereas silicon more than doubled the mean dry matter accumulation in infected plants. The application of silicon to complement host resistance to sheath blight appears to be an effective strategy for disease management in rice, especially when the soil is low or limiting in plant-available silicon.
\end{abstract}

Additional keywords: calcium silicate, Oryza sativa, Rhizoctonia solani

Sheath blight, caused by Rhizoctonia solani Kühn (Thanatephorus cucumeris (Frank) Donk), anastomosis group 1 IA (AG-1 IA) (25), is a potentially devastating disease of rice (Oryza sativa L.) in all temperate and tropical rice production regions, especially in irrigated production systems $(4,8,14,26,29)$. Symptoms of sheath blight include lesions on the base of the leaf sheath near the waterline which are elliptical or oval-shaped and greenish-gray with yellow margins $(8,14)$. High levels of nitrogenous fertilizers, double cropping, high plant populations per unit area, and the utilization of early-maturing, short-stature, high-tillering compact, susceptible cultivars have intensified the severity of this disease in most ricegrowing regions in the world $(4,14,26,29)$.

Although control strategies for sheath blight have centered around the use of foliar fungicides (10), their use is limited due to perceived environmental problems,

Corresponding author: L. E. Datnoff

E-mail: leda@mail.ifas.ufl.edu

This research was supported by the Florida Agricultural Experiment Station, and approved for publication as Journal Series No. R-07655.

Accepted for publication 26 March 2001.

Publication no. D-2001-0530-01R

(C) 2001 The American Phytopathological Society expense, and potential risk of emergence of pathogen populations that could become resistant. Development of cultivars resistant to sheath blight has been slow because the pathogen has an extremely wide host range, resistance shows low heritability, and resistance is linked with poor-yield performing characteristics such as tall plant stature, late maturity, and poor milling quality $(15,19$, 23,26). The highest level of resistance among cultivars grown in the southwestern United States is found in the short- and medium-grain types. These are more like the Japonic rices, although long-grain cultivars, such as Labelle, Bluebelle, and Lebonnet, tend to be more susceptible $(18,29)$.

Resistance to sheath blight is expressed partly as a reduced number of infection cushions produced by $R$. solani, subsequently resulting in fewer and smaller lesions (9). Cultivars with an adequate level of resistance to sheath blight are currently available to farmers in the United States $(21,36)$. Several cultural practices have been applied to minimize the intensity of sheath blight. They include crop rotation, solarization, reduced close spacing of hills in transplanted rice, biological control with potential agents such as Trichoderma spp. and fluorescent pseudomonads, and induced resistance with avirulent strains of $R$. solani or different chemicals and nutrients $(1,28)$.

Other alternatives need to be investigated for sheath blight management. Sili- con fertilization may offer an important and viable alternative for sheath blight control or as a supplement to the use of fungicides, especially where soils are deemed to be low or limiting in plantavailable silicon ( $\mathrm{Si}$ ). Some economically important diseases in rice such as blast (Magnaporthe grisea (Hebert) Barr), brown spot (Cochliobolus miyabeanus (Ito and Kuribayashi in Ito) Drechs ex Dastur), stem rot (Magnaporthe salvinii Catt.), scald (Monographella albescens Theum), and grain discoloration had their intensities reduced by $\mathrm{Si}(5,13,31,34)$. Si also has been shown to suppress the development of sheath blight $(20,35)$.

The purpose of this study was to measure levels of disease development in rice cultivars grown with and without $\mathrm{Si}$ that are high in partial resistance, moderately susceptible, and susceptible to sheath blight. In addition, we wanted to determine whether fertilization with $\mathrm{Si}$ could augment inherent host resistance of susceptible and moderately susceptible cultivars to the same level of resistance exhibited by those cultivars high in partial resistance without $\mathrm{Si}$. A portion of this study was previously published (27).

\section{MATERIAL AND METHODS}

Experiments were conducted under greenhouse conditions from March to June of 1997 at the University of Florida, Everglades Research and Education Center, Belle Glade. The soil type used in all experiments was a Si-deficient Histosol (Terra Ceia muck), collected from the Everglades Agricultural Area, with $3.97 \mathrm{mg}$ $\mathrm{dm}^{-3}$ plant-available Si. Each pot was filled with $2 \mathrm{~kg}$ of muck soil and amended with calcium silicate slag at the rates of 0 and $10 \mathrm{~g} \mathrm{pot}^{-1}$ (approximately 10 metric tons per hectare) 2 days before sowing. Available soluble Si from calcium silicate slag was approximately $22 \%$.

Rice cultivars Jasmine and LSBR-5 (high level of partial resistance), Drew and Kaybonnet (moderately susceptible), and Lemont and Labelle (completely susceptible) were chosen from previous field experiments to represent a range of resistance types to sheath blight $(16,30)$. All cultivars tested were tropical japonicas except for Jasmine, which is an indica type $(17,30)$. Seeds of each cultivar were sown at the rate of 12 seeds per pot. Ten days after 
sowing, each pot was thinned to four plants. No modifications were made to the pots to allow for drainage, and plants were kept under flooded conditions until the end of the experiment.

A virulent isolate of $R$. solani (AG-1 IA), obtained from symptomatic rice plants and provided by F. Lee, University of Arksansas, was used to inoculate plants. The isolate was maintained on acid potato dextrose agar medium (APDA). Inoculum was obtained as follows: the isolate of $R$. solan $i$ was grown on APDA and incubated for 10 days at room temperature to produce mycelia. Wooden toothpicks, $1 \mathrm{~cm}$ in length, were placed in Erlenmeyer flasks containing a shallow layer of potato broth and autoclaved. After autoclaving, 15 toothpicks and five agar plugs, $5 \mathrm{~mm}$ in diameter, obtained from the margin of an actively growing colony of $R$. solani, were transferred to APDA plates. Plates were allowed to incubate for 8 days at room temperature so that $R$. solani could colonize the toothpicks.

Table 1. Concentration of $\mathrm{Si}\left(\mathrm{dag} \mathrm{kg}^{-1}\right)$ in straw of rice cultivars grown in pots nonamended and amended with $\mathrm{Si}^{\text {a }}$

\begin{tabular}{|c|c|c|c|c|c|c|}
\hline \multirow[b]{2}{*}{ Cultivars } & \multicolumn{2}{|c|}{ Experiment 1} & \multicolumn{2}{|c|}{ Experiment 2} & \multicolumn{2}{|c|}{ Experiment 3} \\
\hline & $-\mathbf{S i}$ & $+\mathbf{S i}$ & $-\mathbf{S i}$ & $+\mathbf{S i}$ & $-\mathbf{S i}$ & $+\mathbf{S i}$ \\
\hline Jasmine & 0.56 & 2.10 & 0.72 & 2.98 & 0.76 & 3.15 \\
\hline LSBR-5 & 0.52 & 2.90 & 0.70 & 3.33 & 0.87 & 3.92 \\
\hline Drew & 0.50 & 2.70 & 0.67 & 3.82 & 0.80 & 4.05 \\
\hline Kaybonnet & 0.56 & 2.46 & 0.62 & 3.83 & 0.84 & 4.48 \\
\hline Lemont & 0.52 & 3.48 & 0.70 & 4.03 & 0.83 & 4.53 \\
\hline Labelle & 0.50 & 3.08 & 0.65 & 3.72 & 0.76 & 4.27 \\
\hline FLSD $(P \leq 0.05)$ & 0.06 & 0.32 & 0.08 & 0.36 & 0.09 & 0.30 \\
\hline
\end{tabular}

${ }^{\text {a }} \mathrm{Si}$ analysis in the rice straw was determined by first digesting $0.1 \mathrm{~g}$ of dried tissue, then performing automated colorimetric analysis.

Table 2. Influence of silicon and host plant resistance on severity of sheath blight ${ }^{\mathrm{a}}$

\begin{tabular}{|c|c|c|c|c|c|c|}
\hline \multirow[b]{2}{*}{ Cultivars } & \multicolumn{2}{|c|}{ Experiment 1} & \multicolumn{2}{|c|}{ Experiment 2} & \multicolumn{2}{|c|}{ Experiment 3} \\
\hline & $-\mathbf{S i}$ & $+\mathbf{S i}$ & $-\mathbf{S i}$ & $+\mathbf{S i}$ & $-\mathbf{S i}$ & $+\mathbf{S i}$ \\
\hline Jasmine & 1.70 & 1.20 & 2.50 & 1.00 & 2.92 & 1.00 \\
\hline LSBR-5 & 1.60 & 1.20 & 3.40 & 1.00 & 3.17 & 1.25 \\
\hline Drew & 1.80 & 1.30 & 4.70 & 2.20 & 6.00 & 2.58 \\
\hline Kaybonnet & 2.13 & 1.40 & 5.60 & 2.10 & 6.50 & 2.67 \\
\hline Lemont & 2.50 & 1.70 & 7.90 & 4.00 & 7.75 & 3.33 \\
\hline Labelle & 2.85 & 1.65 & 6.70 & 3.70 & 7.42 & 3.17 \\
\hline FLSD $(P \leq 0.05)$ & 0.71 & 0.49 & 1.07 & 1.05 & 0.55 & 0.67 \\
\hline
\end{tabular}

${ }^{a}$ Severity of sheath blight was scored on a scale ranging from 0 to 9 , which is based on the relative lesion height on the whole plant.

Table 3. Influence of silicon and host plant resistance on the total area under the vertical lesion extension progress curve ${ }^{\text {a }}$

\begin{tabular}{lrrrrrrrr}
\hline & \multicolumn{2}{c}{ Experiment $\mathbf{1}$} & & \multicolumn{2}{c}{ Experiment 2 } & & \multicolumn{2}{c}{ Experiment 3 } \\
\cline { 2 - 3 } \cline { 8 - 9 } Cultivars & $-\mathbf{S i}$ & $\mathbf{+} \mathbf{S i}$ & & $-\mathbf{S i}$ & $\mathbf{+} \mathbf{S i}$ & & $-\mathbf{S i}$ & $+\mathbf{S i}$ \\
\hline Jasmine & 97.59 & 36.90 & & 154.58 & 48.83 & & 203.15 & 126.25 \\
LSBR-5 & 121.45 & 47.43 & & 132.00 & 69.28 & & 203.08 & 112.94 \\
Drew & 98.30 & 78.43 & & 201.21 & 114.30 & & 426.25 & 253.94 \\
Kaybonnet & 105.91 & 69.58 & & 244.28 & 63.62 & & 385.89 & 278.83 \\
Lemont & 123.14 & 77.03 & & 283.30 & 228.00 & & 528.54 & 236.11 \\
Labelle & 122.03 & 81.95 & & 251.75 & 149.43 & & 415.80 & 231.39 \\
FLSD $(P \leq 0.05)$ & 20.60 & 42.90 & & 70.49 & 58.93 & & 75.98 & 54.11 \\
\hline
\end{tabular}

a Total area under the vertical lesion extension progress curve was obtained by summing the area under the vertical lesion extension for all three sheaths in each experiment. maintained within this plastic mist chamber, ranging between 89 and $96 \%$ with a humidifier (Herrmidifier 500 Co., Inc., Lancaster, PA). Plants also were maintained under natural light.

Sheath blight progress on the plant was evaluated by measuring the vertical lesion extension $(\mathrm{mm})$ in the inoculated sheath as well as on the two sheaths above. In experiment 1 , the evaluations in the inoculated sheath were made at $4,5,6,7,8,9$, and 10 days postinoculation; for the second sheath at 10,12, 15, 17, 19, 21, and 23 days postinoculation; and for the third sheath at 21, 23, 24, 27, and 29 days postinoculation. In experiment 2 , the evaluations in the inoculated sheath were made at $4,5,6,7$, and 8 days postinoculation; for the second sheath at $5,6,7,8,10$, 12,14 , and 15 days postinoculation; and for the third sheath at $12,14,15,16,19$, and 20 days postinoculation. In experiment 3 , the evaluations in the inoculated sheath were made at $4,5,6,7$, and 9 days postinoculation; for the second sheath at 5 , $6,7,9,11,14,16$, and 18 days postinoculation; and for the third sheath at 14, 16, 18, 20 , and 21 days postinoculation. Data from each sheath in each treatment and experiment were used to construct the vertical lesion extension progress curve. Area under the vertical lesion extension progress curve (AUVLEPC) for each sheath in each plant, replication, treatment, and experiment was computed using the trapezoidal integration of vertical lesion extension progress curve over time using the formula proposed by Shaner and Finney (33). Total AUVLEPC represents the sum of the AUVLEPC from all sheaths.

Severity of sheath blight was scored using a scale ranging from 0 to 9 , which is based on relative lesion height on the whole plant (12). The scale is as follows: $0=$ no infection; 1 = lesions limited to lower $20 \% ; 3=$ lesions limited to lower 20 to $30 \%$; $5=$ lesions limited to lower 31 to $45 \%$; $7=$ lesions limited to lower 46 to $65 \%$; and $9=$ lesions infecting more than $65 \%$ of plant height. Percentage of infected tillers, dry matter accumulation for inoculated and noninoculated plants, and silicon concentration in straw also were determined.

Dry matter accumulation of plants was determined at 62 to 71 days after sowing, depending on the experiment. Leaves and culms were ground to pass through a 40mesh screen with a Thomas-Wiley mill (Thomas Scientific, Swedesboro, NJ). The concentration of silicon in tissue samples was determined by first digesting $0.1 \mathrm{~g}$ of dried tissue, then performing automated colorimetric analysis (6). Results obtained were expressed in decagrams (dag) of $\mathrm{Si}$ per $\mathrm{kg}$ of plant tissue.

A $2 \times 6 \times 2$ factorial experiment, consisting of two levels of $\mathrm{Si}$, six cultivars, and inoculated and noninoculated (control) plants, was arranged in a completely randomized design with five replications. Val- 
ues obtained for each variable were analyzed by analysis of variance (ANOVA). For dry matter accumulation, ANOVA included the factor of inoculated and noninoculated plants. Mean comparisons were conducted with Fisher's protected least significant difference (FLSD, $P \leq 0.05$ ) test. Single degree-of-freedom contrasts were used to make comparisons between specific cultivar groups, nonamended and amended with $\mathrm{Si}$. Arcsine transformation was used in the analysis of the percentage of infected tillers.
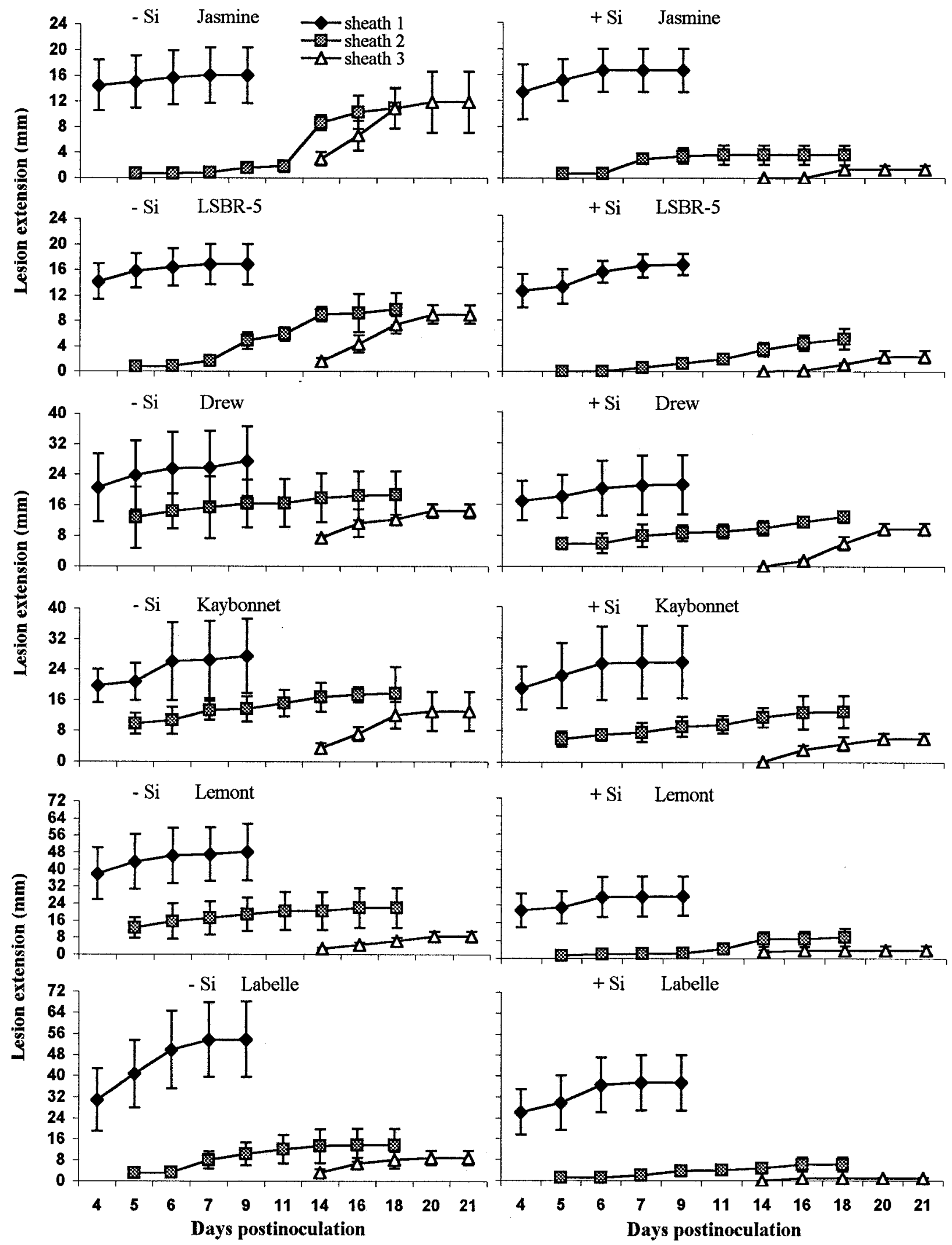

Fig. 1. Vertical lesion extension (mm) progress curves on rice cultivars Jasmine, LSBR-5, Drew, Kaybonnet, Lemont, and Labelle fertilized (+ Si) or not $(-\mathrm{Si})$ with silicon. Data points are means of 20 plants in five replications for each sheath in each treatment. Evalutions started 4 days postinoculation when the first lesion was observed on sheath 1 (inoculated sheath). Bars represent standard deviation of the mean. Three experiments were conducted with consistent results and the data presented represent the third experiment. 
The experiment was repeated three times and data from repeated experiments were not pooled for analysis because there was no interaction between experiment and treatment effects. Data were subjected to analyses using the Statistical Analysis System (SAS Institute, Cary, NC).

\section{RESULTS AND DISCUSSION}

Silicon and cultivar treatments had highly significant effects $(\mathrm{P} \leq 0.05)$ on silicon concentration in straw, severity of sheath blight, total area under the vertical lesion extension curve, and percentage of infected tillers in all experiments (data not shown). The cultivar $\times$ silicon interaction was also significant $(P \leq 0.05)$ for these variables, requiring the analysis of $\mathrm{Si}$ means by cultivar.

Mean $\mathrm{Si}$ concentration in straw increased markedly with addition of calcium silicate slag (range of 73 to $85 \%, 76$ to $84 \%$, and 76 to $82 \%$, respectively, in experiments 1,2 , and 3 over all cultivars), as compared to $\mathrm{Si}$-nonamended treatments (Table 1). Variation among cultivars was significant $(\mathrm{P} \leq 0.05)$ for $\mathrm{Si}$ concentration in Si-nonamended treatments only in experiments 2 and 3. However, the range among cultivars was very narrow. For the Si-amended treatment, cultivars varied significantly $(\mathrm{P} \leq 0.05)$ for $\mathrm{Si}$ concentration in plant tissue (Table 1). In experiment 1, Jasmine had the lower plant-tissue $\mathrm{Si}$ concentration and differed significantly from other cultivars. In experiment 2 , the highest $\mathrm{Si}$ values were determined on Drew, Kaybonnet, Lemont, and Labelle, which differed significantly from Jasmine and LSBR-5. In experiment 3, only Kaybonnet, Lemont and Labelle, with the greatest values of $\mathrm{Si}$ concentration, differed significantly from Jasmine and LSBR-5. Genotypic differences for concentration of $\mathrm{Si}$ in Jasmine and LSBR-5 observed in all experiments could have resulted in differential uptake and utilization of this element in comparison to the other cultivars.

Increasing $\mathrm{Si}$ concentration in straw significantly reduced the severity of sheath blight on cultivars Jasmine and LSBR-5 that are high in partial resistance; on the moderately susceptible cultivars Drew and Kaybonnet, and on the susceptible cultivars
Lemont and Labelle, by 27, 29, and 37\% respectively in experiment $1 ; 66,58$, and $47 \%$ in experiment 2 , and 63,58 , and $57 \%$ respectively in experiment 3 , as compared to these cultivars without $\mathrm{Si}$ (Table 2).

Total AUVLEPC also decreased significantly on cultivars high in partial resistance, moderately susceptible and susceptible by 62,28 , and $35 \%$ respectively in experiment $1 ; 59,60$, and $30 \%$ in experiment 2 , and 41,34 , and $51 \%$ respectively in experiment 3 , as compared to these cultivars without Si (Table 3 and Fig. 1).

To determine whether the application of Si to moderately susceptible and susceptible cultivars could suppress the severity of sheath blight and the total AUVLEPC to those cultivars high in partial resistance that had not been treated with $\mathrm{Si}$, selected cultivar-Si combinations were compared by single degree of freedom contrasts (Table 4). In all experiments, the combination of Drew and Kaybonnet, Lemont and Labelle, or these cultivars analyzed separately, plus silicon reduced the severity of sheath blight to the same statistical level as that for the cultivars Jasmine and LSBR-5 high in partial resistance without $\mathrm{Si}$. Si fertilization also reduced the total AUVLEPC for Drew and Kaybonnet and Lemont and Labelle in experiment 1; for Drew and Kaybonnet and Labelle in experiment 2, and for Drew and Lemont and Labelle in experiment 3, to the same statistical level as Jasmine and LSBR-5 without Si $(\mathrm{P} \leq 0.05)$ (Table 4). Little information is currently available for sheath blight control by addition of Si. According to Mathai et al. (20), application of Si had a significant effect in reducing the intensity of sheath blight, even though the difference between the high and low levels of Si was not statistically significant. Winslow et al. (35) reported only that Si reduced the severity of sheath blight in irrigated indica rice genotypes as compared to japonica upland rice genotypes and intermediate groups. However, in this study, we demonstrated that $\mathrm{Si}$ reduced sheath blight development in both tropical japonicas and an indica type. This suggests that enhanced sheath blight resistance by $\mathrm{Si}$ is not limited to indica types. Future research needs to be conducted on greater populations of indi- cas and japonicas to better understand the scope of Si-responsive genotypes.

Fertilization with Si reduced the percentage of infected tillers by $R$. solani by a range of 20 to $86 \%, 19$ to $85 \%$, and 9 to $76 \%$ respectively in experiments 1,2 , and 3 , over all cultivars (Table 5). Variation among cultivars was significant in $\mathrm{Si}$ nonamended treatment only in experiments 1 and 2 . In all experiments, for the $\mathrm{Si}$ amended treatment, Jasmine and LSBR-5, which are high in partial resistance to sheath blight, had the lowest percentage of infected tillers, as compared to Lemont and Labelle, which are known to be sheath blight-susceptible. The decrease in the number of diseased hills is particularly important to slow the horizontal spread of $R$. solani in the field and consequently reduce yield loss $(8,26)$.

A physical barrier of $\mathrm{Si}$ in the cuticle layer of the leaf sheath as affirmed by Yoshida et al. (37) would likely reduce lesion extension, as well as disease intensity in general, on Si-treated plants. Volk et al. (34) hypothesized that blast lesion size could be reduced by organosilicon compounds in the walls of epidermal cells, and Inanaga et al. (11) later proved that Si does indeed form complexes with organic compounds in these cells. Seebold et al. (32) demonstrated that the rate of blast lesion expansion in several rice cultivars decreased from 0.8 to $0.43 \mathrm{~mm} /$ day as the rate of calcium silicate slag increased from 0 to $10 \mathrm{~T} \mathrm{ha}^{-1}$. An induced resistance by $\mathrm{Si}$ might also have contributed to reducing sheath blight intensity, not accounted for by the physical barrier of $\mathrm{Si}$ in the cuticle layer. In rice, the exact mechanism(s) by which Si reduces the intensity of sheath blight, and other diseases such as blast, is unknown. Other researchers have suggested that $\mathrm{Si}$ acts in crops such as cucumber and barley to stimulate host defense mechanisms to pathogenesis, such as increasing phenol content and the activity of chitinases, $\beta$-1,3-glucanases, peroxidase, $\beta$-glucosidase, phenylalanine ammonialyase, and polyphenoloxidase $(2,3,7,22)$.

A significant interaction was detected between cultivar $\times$ inoculated and noninoculated plants and silicon $\times$ inoculated and noninoculated plants (data not shown). In all experiments, for all cultivars, non-

Table 4. Single degree of freedom contrasts for comparisons between specific groups of cultivars nonamended and amended with Si on severity of sheath blight (Sev) and total area under the vertical lesion extension progress curve (TAUVLEPC)

\begin{tabular}{|c|c|c|c|c|c|c|c|c|}
\hline \multirow{2}{*}{\multicolumn{3}{|c|}{ Cultivar groups }} & \multicolumn{6}{|c|}{ Sum of square ${ }^{a}$} \\
\hline & & & \multicolumn{2}{|c|}{ Experiment 1} & \multicolumn{2}{|c|}{ Experiment 2} & \multicolumn{2}{|c|}{ Experiment 3} \\
\hline$-\mathbf{S i}$ & & $+\mathbf{S i}$ & $\mathbf{S e v}^{\mathbf{a}}$ & TAUVLEPC & Sev & TAUVLEPC & Sev & TAUVLEPC \\
\hline Jasmine and LSBR-5 & vs. & Drew and Kaybonnet & $1.800^{\text {ns }}$ & $3571.128^{\mathrm{ns}}$ & $1.800^{\text {ns }}$ & $21978.450^{\text {ns }}$ & $4.167^{\mathrm{ns}}$ & $96076.760^{* *}$ \\
\hline Jasmine and LSBR-5 & vs. & Drew & $1.633^{\mathrm{ns}}$ & $206.719^{\text {ns }}$ & $0.833^{\text {ns }}$ & $813.802^{\mathrm{ns}}$ & $3.361^{\mathrm{ns}}$ & $41327.501^{\mathrm{ns}}$ \\
\hline Jasmine and LSBR-5 & vs. & Kaybonnet & $0.833^{\text {ns }}$ & $6923.602^{\mathrm{ns}}$ & $1.633^{\mathrm{ns}}$ & $45610.502^{\mathrm{ns}}$ & $2.250^{\mathrm{ns}}$ & $91733.266^{*}$ \\
\hline Jasmine and LSBR-5 & vs. & Lemont and Labelle & $0.013^{\text {ns }}$ & $3315.313^{\mathrm{ns}}$ & $39.200^{\mathrm{ns}}$ & $88711.200^{* *}$ & $1.041^{\mathrm{ns}}$ & $28042.091^{\mathrm{ns}}$ \\
\hline Jasmine and LSBR-5 & vs. & Lemont & $0.033^{\mathrm{ns}}$ & $3136.519^{\text {ns }}$ & $32.033^{\text {ns }}$ & $149495.502^{* *}$ & $1.361^{\mathrm{ns}}$ & $22236.101^{\mathrm{ns}}$ \\
\hline Jasmine and LSBR-5 & vs. & Labelle & $0.133^{\text {ns }}$ & $1445.602^{\mathrm{ns}}$ & $20.833^{\mathrm{ns}}$ & $9946.302^{\mathrm{ns}}$ & $0.250^{\mathrm{ns}}$ & $16782.881^{\mathrm{ns}}$ \\
\hline
\end{tabular}

a ns, ${ }^{*}$, and ${ }^{* *}=$ nonsignificant, significant at 0.05 and 0.01 levels of probability. 
inoculated plants had significantly greater dry matter accumulation when compared to inoculated plants (Table 6). Dry matter accumulation for noninoculated plants increased relative to the inoculated plants by a range of 46 to $96 \%, 45$ to $137 \%$, and 24 to $162 \%$ respectively in experiments 1 , 2 , and 3 (Table 6). For inoculated plants, dry matter accumulation on Jasmine and LSBR-5 was significantly higher compared to Lemont in experiment 1, and to Drew, Kaybonnet, Lemont, and Labelle in both experiments 2 and 3 (Table 6). In the absence of disease, $\mathrm{Si}$ enhanced dry matter accumulation by 13,25 , and $15 \%$ respectively in experiments 1,2 , and 3 . However, in the presence of sheath blight, Si more than doubled the mean dry matter accumulation in experiment $3(38 \%)$, had a little effect in experiment 2 (28\%), and had no effect in experiment 1 (13\%) (Table 6). Increases in dry matter accumulation by $\mathrm{Si}$ for inoculated plants could be attributed to a decrease in the intensity of sheath blight, and more favorable plant nutrition for both inoculated and noninoculated plants. It is known that sheath blight infection may change the dynamic balance of synthesis and decomposition of chlorophyll pigments and rate of photosynthesis in rice (24), due to the presence of several large lesions on leaf sheath and leaf blades of the rice plant.

The results presented in this study provide evidence that $\mathrm{Si}$ can be used successfully to enhance the level of resistance to sheath blight, especially in moderately susceptible and susceptible cultivars grown in soils low or limited in plant-available $\mathrm{Si}$. This becomes especially important when cultivars with a satisfactory level of resistance to sheath blight are not available for commercial use.

\section{ACKNOWLEDGMENTS}

We thank Rosie L. Monroe and Theresa E. Sanford for their technical assistance, and Christopher W. Deren and Thomas A. Kucharek for their critical reviews and suggestions.

\section{LITERATURE CITED}

1. Belmar, S. B., Jones, R. K., and Starr, J. L. 1987. Influence of crop rotation on inoculum density of Rhizoctonia solani and sheath blight incidence in rice. Phytopathology 77:1138-1143.

2. Carver, T. L. W., Zeyen, R. J., and Ahlstrand, G. G. 1987. The relationship between insoluble silicon and success or failure of attempted primary penetration by powdery mildew (Erysiphe graminis) germlings on barley. Physiol. Mol. Plant Pathol. 31:133-148.

3. Chérif, M., Benhamou, N., Menzies, J. G., and Bélanger, R. R. 1992. Silicon induced resistance in cucumber plants against Pythium ultimum. Physiol. Mol. Plant Pathol. 41:411425.

4. Dath, A. P. 1990. Sheath blight disease of rice and its management. Associated Publishing Company, New Delhi.

5. Datnoff, L. E., Deren, C. W., and Snyder, G. H. 1997. Silicon fertilization for disease management of rice in Florida. Crop Prot. 16:525531

6. Elliot, C. L., and Snyder, G. H. 1991. Autoclave-induce digestion for the colorimetric determination of silicon in rice straw. J. Agric. Food Chem. 39:1118-1119.

7. Fawe, A., Abou-Zaid, M., Menzies, J. G., and Bélanger, R. R. 1998. Silicon-mediated accumulation of flavonoid phytoalexins in cucum-

Table 5. Influence of silicon and host plant resistance on the percentage of infected tillers ${ }^{\text {a }}$

\begin{tabular}{|c|c|c|c|c|c|c|}
\hline \multirow[b]{2}{*}{ Cultivars } & \multicolumn{2}{|c|}{ Experiment 1} & \multicolumn{2}{|c|}{ Experiment 2} & \multicolumn{2}{|c|}{ Experiment 3} \\
\hline & $-\mathbf{S i}$ & $+\mathbf{S i}$ & $-\mathbf{S i}$ & $+\mathbf{S i}$ & $-\mathbf{S i}$ & $+\mathbf{S i}$ \\
\hline Jasmine & 17.50 & 2.50 & 50.00 & 7.50 & 90.28 & 21.87 \\
\hline LSBR-5 & 12.50 & 10.00 & 50.00 & 20.00 & 90.28 & 49.31 \\
\hline Drew & 25.00 & 17.50 & 62.50 & 45.00 & 100.00 & 72.92 \\
\hline Kaybonnet & 28.13 & 12.50 & 70.00 & 42.50 & 94.45 & 66.67 \\
\hline Lemont & 42.50 & 35.00 & 100.00 & 47.50 & 95.83 & 87.50 \\
\hline Labelle & 40.00 & 32.50 & 65.00 & 52.50 & 91.67 & 79.17 \\
\hline FLSD $(P \leq 0.05)$ & 22.31 & 21.52 & 26.18 & 25.52 & 12.05 & 20.55 \\
\hline
\end{tabular}

${ }^{a}$ Values were arcsine transformed before analysis.

Table 6. Influence of silicon and host plant resistance on dry matter accumulation (g per 4 plants) ${ }^{\mathrm{a}}$

\begin{tabular}{|c|c|c|c|c|c|c|}
\hline \multirow[b]{2}{*}{ Cultivars } & \multicolumn{2}{|c|}{ Experiment 1} & \multicolumn{2}{|c|}{ Experiment 2} & \multicolumn{2}{|c|}{ Experiment 3} \\
\hline & Inoculated & Noninoculated & Inoculated & Noninoculated & Inoculated & oninoculated \\
\hline Jasmine & 11.69 & 17.10 & 9.41 & 13.65 & 7.86 & 9.78 \\
\hline LSBR-5 & 9.79 & 15.70 & 9.03 & 13.83 & 6.51 & 11.46 \\
\hline Drew & 10.60 & 18.37 & 7.47 & 15.35 & 5.79 & 11.82 \\
\hline Kaybonnet & 9.87 & 18.22 & 7.15 & 14.85 & 4.85 & 12.28 \\
\hline Lemont & 8.61 & 16.05 & 6.92 & 15.97 & 4.57 & 11.99 \\
\hline Labelle & 10.84 & 21.30 & 7.24 & 19.54 & 5.62 & 12.75 \\
\hline $\begin{array}{l}\text { FLSD } \\
(P \leq 0.05)\end{array}$ & 1.17 & 3.45 & 0.93 & 7.59 & 0.68 & 1.73 \\
\hline \multicolumn{7}{|l|}{ Silicon } \\
\hline$-\mathrm{Si}$ & 9.63 & 16.73 & 7.05 & 13.84 & 4.94 & 10.86 \\
\hline$+\mathrm{Si}$ & 10.83 & 18.85 & 9.03 & 17.34 & 6.80 & 12.50 \\
\hline $\begin{array}{l}t \text { test } \\
(P \leq 0.05)\end{array}$ & 0.67 & 1.99 & 0.53 & 2.36 & 0.39 & 0.99 \\
\hline
\end{tabular}

a Dry matter accumulation was determined 62 to 71 days after sowing depending on the experiment. ber. Phytopathology 88:396-401.

8. Gangopadhyay, S., and Chakrabarti, N. K. 1982. Sheath blight of rice. Rev. Plant Pathol. 61:451-460.

9. Groth, D. E., and Nowick, E. M. 1992. Selection for resistance to rice sheath blight through number of infection cushions and lesion type. Plant Dis. 76:721-723.

10. Groth, D. E., Rush, M. C., and Lindberg, G. D. 1990. Foliar fungicides for control of rice diseases in the United States. Pages 31-52 in Pest Management in Rice. B. T. Grayson, M. B. Green, and L. G. Copping, eds. Elsevier Applied Science, London.

11. Inanaga, S., Okasaka, A., and Tanaka, S. 1995. Does silicon exist in association with organic compounds in rice plant? Soil Sci. Plant Nutr. 11:111-117.

12. IRRI. 1996. Standard Evaluation System for Rice. 4rd Edition. International Rice Testing Program, International Rice Research Institute, Manila, The Philippines.

13. Korndörfer, G. H., Datnoff, L. E., and Corrêa, G. F. 1999. Influence of silicon on grain discoloration and upland rice grown on four savanna soils from Brazil. J. Plant Nutr. 22:93102.

14. Lee, F. N., and Rush, M. C. 1983. Rice sheath blight: A major rice disease. Plant Dis. 67:829-832.

15. Li, Z., Pinson, S. R. M., Marchetti, M. A., Stansel, J. W., and Park, W. D. 1995. Characterization of quantitative trait loci (QTLs) in cultivated rice contributing to field resistance to sheath blight (Rhizoctonia solani). Theor Appl. Genet. 91:382-388.

16. Louisiana Agricultural Experiment Station. 1994. 86th Annual Research Report, Rice Research Station, LSU, Crowley, LA.

17. MacKill, D. J. 1995. Classifying japonica rice cultivars with RAPD markers. Crop Sci. 35:889-894

18. Marchetti, M. A. 1983. Potential impact of sheath blight on rice yield and milling quality of short-statured rice lines in the southern United States. Plant Dis. 67:162-165.

19. Marshall, D. S., and Rush, M. C. 1980. Relation between infection by Rhizoctonia solani and Rhizoctonia oryzae and disease severity in rice. Phytopathology 70:941-946.

20. Mathai, G., Paily, P. V., and Menon, M. R. 1977. Effect of fungicides and silica in the control of sheath blight disease of rice caused by Corticium sasakii (Shiriai). Agric. Res. J. Kerala 19:79-83.

21. McClung, A. M., Marchetti, M. A., Webb, B. D., Bollich, C. N. 1997. Registration of 'Jefferson' rice. Crop Sci. 37:629-630.

22. Menzies, J. G., Ehret, D. L., Glass, A. D. M., and Samuels, A. L. 1991. The influence of silicon on cytological interactions between Sphaerotheca fulginea and Cucumis sativus. Physiol. Mol. Plant Pathol. 39:403-414.

23. Min, A., Sciumbato, G. L., Kanter, D. G., Jackson, B. R., and Damicone, J. P. 1990. Identification of rice sheath blight resistance. Biol. Cult. Tests Control Plant Dis. 5:66.

24. Naidu, D.V., Rao, B. S., Murty, P. S. S. 1981 Infuence of sheath blight infection on the levels of chlorophyll and $14 \mathrm{CO}_{2}$ uptake in rice. Indian Phytopathol. 34:30-33.

25. Ogoshi, A. 1987. Ecology and pathogenicity of anastomosis and intraspecific groups of Rhizoctonia solani Kühn. Annu. Rev. Phytopathol. 25:125-143.

26. Ou, S. H. 1985. Rice Diseases, 2nd ed. Commonwealth Mycological Institute, Kew, England.

27. Rodrigues, F. A., Datnoff, L. E., Korndörfer, G. H., Rush, M. C., Seebold, K. W., and Linscombe, S. D. 1998. Effects of calcium silicate and resistance on the development of sheath blight in rice. Page 142 in: Proc. 27th 
Rice Technical Working Group, Texas Agricultural Experiment Station, Reno, Nevada, 14 March.

28. Roy, A. K. 1996. Innovative methods to manage sheath blight of rice. J. Mycopathol. Res. 34:13-19.

29. Rush, M. C., and Lee, F. N. 1992. Sheath Blight. Pages 22-23 in: Compendium of rice diseases. R. K. Webster and P. S. Gunnell eds. APS Press, St. Paul, MN

30. Rush, M. C., Linscombe, S. D., Pan, X. B., Sha, X. Y., Shao, Q. M., and Stetina, S. R. 1998. Development of sheath blight resistant lines. Page 129 in: Proc. 27th Rice Technical Working Group, Texas Agricultural Experi- ment Station, Reno, Nevada, 1-4 March.

31. Savant, N. K., Snyder, G. H., and Datnoff, L. E. 1997. Silicon management and sustainable rice production. Adv. Agron. 58:151-199.

32. Seebold, K. W., Kucharek, T. A., Datnoff, L. E., Correa-Victoria, F. J., and Marchetti, M. A. 2001. The influence of silicon on components of resistance to blast in susceptible, partially resistant, and resistant cultivars of rice. Phytopathology 91:63-69.

33. Shaner, G., and Finney, R. E. 1977. The effect of nitrogen fertilization on the expression of slow-mildewing resistance in Knox wheat. Phytopathology 67:1051-1056.

34. Volk, R. J., Kahn, R. P., and Weintraub, R. L.
1958. Silicon content of the rice plant as a factor in influencing its resistance to infection by the rice blast fungus Piricularia oryzae. Phytopathology 48:179-184.

35. Winslow, M. D. 1992. Silicon, disease resistance, and yield of rice genotypes under upland cultural conditions. Crop Sci. 32:1208-1213.

36. Xie, Q. J., Linscombe, S. D., Rush, M. C., and Jodari-Karimi, F. 1992. Registration of LSBR-33 and LSBR-5 sheath blight resistant germoplasm lines of rice. Crop Sci. 32:507.

37. Yoshida, S., Ohnishi, Y., and Kitagishi, K. 1962. Chemical forms, mobility and deposition of silicon in rice plant. Soil Sci. Plan Nutr. 8:15-21. 